\title{
Fluid overload after coronary artery bypass graft in patients on maintenance hemodialysis is associated with prolonged time on mechanical ventilation
}

Sirlei Cristina da Silva ${ }^{1,2^{*}}$, Fernanda Marciano Consolim-Colombo ${ }^{1,3}$, Renata Gomes Rodrigues ${ }^{3}$, Fábio Antonio Gaiotto ${ }^{1}$, Ludhmila Abrahão Hajjar ${ }^{1}$, Rosa Maria Affonso Moysés ${ }^{2}$ and Rosilene Motta Elias 2,3

\begin{abstract}
Background: Fluid overload is a risk factor for morbidity, mortality, and prolonged ventilation time after surgery. Patients on maintenance hemodialysis might be at higher risk. We hypothesized that fluid accumulation would be directly associated with extended ventilation time in patients on hemodialysis, as compared to patients with chronic kidney disease not on dialysis (CKD3-4) and patients with normal renal function (reference group).

Methods: This is a prospective observational study that included patients submitted to isolated and elective coronary artery bypass surgery, divided in 3 groups according to time on mechanical ventilation: $<24 \mathrm{~h}, 24-48 \mathrm{~h}$ and $>48 \mathrm{~h}$. The same observer followed patients daily from the surgery to the hospital discharge. Cumulative fluid balance was defined as the sum of daily fluid balance over the first 5 days following surgery.

Results: Patients requiring more than $48 \mathrm{~h}$ of ventilation (5.3\%) had a lower estimated glomerular filtration rate, were more likely to be on maintenance dialysis, had longer anesthesia time, needed higher dobutamine and noradrenaline infusion following surgery, and had longer hospitalization stay. Multivariate analysis revealed that the fluid accumulation, scores of sequential organ failure assessment in the day following surgery, and the renal function (normal, chronic kidney disease not on dialysis and maintenance hemodialysis) were independently associated with time in mechanical ventilation. Among patients on hemodialysis, the time from the surgery to the first hemodialysis session also accounted for the time on mechanical ventilation.

Conclusions: Fluid accumulation is an important risk factor for lengthening mechanical ventilation, particularly in patients on hemodialysis. Future studies are warranted to address the ideal timing for initiating dialysis in this scenario in an attempt to reduce fluid accumulation and avoid prolonged ventilation time and hospital stay.
\end{abstract}

Keywords: Hemodialysis, Intensive care unit, Renal disease, Dialysis, Chronic kidney disease

\footnotetext{
* Correspondence: sirlei.silva@hc.fm.usp.br

'Instituto do Coração, Hospital das Clinicas HCFMUSP, Universidade de São Paulo, São Paulo, Brazil

${ }^{2}$ Nephrology, Hospital das Clinicas HCFMUSP, Universidade de São Paulo, São Paulo, Brazil

Full list of author information is available at the end of the article
}

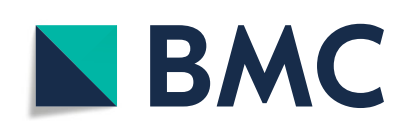

(- The Author(s). 2020 Open Access This article is licensed under a Creative Commons Attribution 4.0 International License, which permits use, sharing, adaptation, distribution and reproduction in any medium or format, as long as you give appropriate credit to the original author(s) and the source, provide a link to the Creative Commons licence, and indicate if changes were made. The images or other third party material in this article are included in the article's Creative Commons licence, unless indicated otherwise in a credit line to the material. If material is not included in the article's Creative Commons licence and your intended use is not permitted by statutory regulation or exceeds the permitted use, you will need to obtain permission directly from the copyright holder. To view a copy of this licence, visit http://creativecommons.org/licenses/by/4.0/. The Creative Commons Public Domain Dedication waiver (http://creativecommons.org/publicdomain/zero/1.0/) applies to the data made available in this article, unless otherwise stated in a credit line to the data. 


\section{Background}

Coronary artery bypass grafting (CABG) is indicated as a treatment of ischemic heart disease for patients with chronic kidney disease [1] (CKD), a population with a high mortality rate. Respiratory failure is common during the postoperative period following CABG and continues to be a major cause of morbidity in this population [2, 3]. Mechanical ventilation in the postoperative period is needed until normothermia and hemodynamic stability is achieved [4]. Intubation time is the strongest independent predictor of 30-day and 1-year mortality among patients undergoing CABG [5]. Modern surgical techniques, advances in anesthesia and myocardial protection have contributed to reducing the ventilation time, which is increased by age and comorbidities [2]. Prolonged mechanical ventilation (PMV) has been described in 2.9 to $22 \%$ of patients submitted to CABG $[2,6]$. The first $24 \mathrm{~h}$ of mechanical ventilation are dependent on multiple factors, including a patient's preoperative condition, the complexity of surgical procedure, as well as intra- and postoperative complications [5].

Hemodynamic instability after cardiovascular surgery is a situation often managed with fluid administration. However, establishing goals of volume management in patients with renal failure on maintenance hemodialysis is challenging. Since these patients are usually anuric, fluid accumulation is not uncommon. The association between positive fluid balance and deleterious effects on lung function and prolonged mechanical ventilation has been described [7, 8]. Indeed, positive fluid balance during the first 3 to 7 days can increase in-hospital mortality even in non-cardiac, postsurgical patients [9]. Negative fluid balance, on the other hand, is associated with lower postoperative mortality following both cardiovascular surgery [8, 10] and non-cardiovascular surgery [7].

Anuria and the high prevalence of comorbidities such as hypertension, diabetes and advanced age increase the odds of a positive fluid balance, and PMV in these patients [11]. The goal of the current study is to access the time on mechanical ventilation after CABG, comparing patients with normal renal function, patients with CKD not on dialysis, and patients on regular maintenance hemodialysis. We hypothesized that patients on dialysis will present a more positive fluid balance and, therefore, prolonged time on mechanical ventilation.

\section{Methods}

Patients were recruited at the Instituto do Coração (InCor), Universidade de São Paulo. Inclusion criteria were as follow: consecutive adult patients submitted to an elective CABG in the period between July 2015 and

\section{Cardiothoracic surgery during the study period $\mathrm{N}=3512$

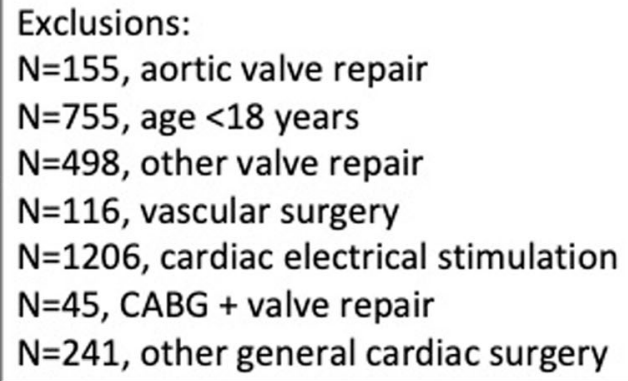

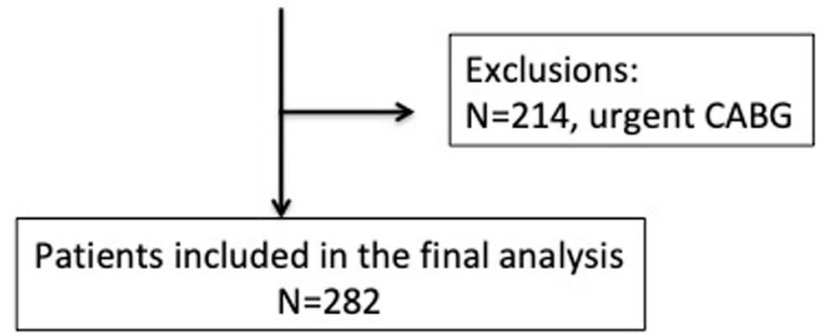

Fig. 1 Flow diagram for patient inclusion and exclusion 
March 2017. Flow diagram for patient inclusion and exclusion is shown in a supplementary file (Fig. 1). For analysis purpose patients were fitted according to mechanical ventilation length after surgery (less than $24 \mathrm{~h}, 24-48 \mathrm{~h}$ and more than $48 \mathrm{~h}$ ). The exclusion criterion was patients submitted to valve replacement surgery plus CABG.

The Local Ethics Committee at the Hospital das Clínicas da Faculdade de Medicina da Universidade de São Paulo has approved the research (Cappesq \#45529815.6.0000.0068).

\section{Variables of interest and definitions}

Clinical, biochemical and demographic data were prospectively collected from charts including age, gender, weight, presence of diabetes, and serum creatinine. Postoperative data collected included: aortic cross-clamping time ( $\mathrm{min})$, cardiopulmonary bypass time $(\mathrm{min})$, surgery time (min), use of intra-aortic balloon pump (\% of patients), anesthesia time ( $\mathrm{min}$ ), ventilation time (also categorized in $<24,24-48 \mathrm{~h}$ and $>48 \mathrm{~h}$ ), sequential organ failure assessment - SOFA (scores) and use of dobutamine and noradrenaline.

Renal function was expressed as estimated glomerular filtration rate (eGFR), calculated by the Chronic Kidney Disease Epidemiology - CKD-EPI 2009 equation [12]. Patients on renal replacement therapy were submitted to a hemodialysis session on the day before surgery, according to Hospital protocol.

The same observer followed each patient daily from the surgery to the hospital discharge. To identify the potential risk of mortality, the SOFA score was applied. In addition, we calculated the same score without taking into account the renal component. Daily fluid balance was calculated during intensive care unit (ICU) as the difference in intakes and outputs, not including insensible losses, taking into account: volume of fluid intake (including saline, drugs and blood), and losses (ultrafiltration during hemodialysis, diuresis, and blood loss, quantified as volume drained in the thoracic suction tube) [13].

A positive balance defined fluid accumulation. Cumulative fluid balance was defined as the sum of daily fluid over the first 5 days after CABG ( $\Sigma$ fluid balance). Fluid overload (FO) was defined as $10 \%$ after adjustment for body weight (FO/body weight) and it was calculated as following: \% fluid overload = (total fluid in - total fluid out)/admission body weight $\times 100$ ), expressed as percentage [13].

\section{Statistical analysis}

Continuous data are expressed as mean \pm standard deviation (SD) or median $(25,75)$, whereas categorical data are expressed as frequencies and percentages. Comparison among the 3 groups was done by ANOVA (if normally distributed) or Kruskall-Wallis (if non-normally distributed). Categorical data were compared by Fisher's exact test or chi-squared, as appropriate. Relationships between single variables were examined by Spearman. Multivariate regression analyses were used to assess factors associated with ventilation time and independent variables were selected from univariate analysis. We also performed a stepwise linear regression, with $p<0.05$ to enter and $p>0.1$ to remove in the group of patients on hemodialysis to test age, SOFA scores without the renal component, and the accumulated fluid balance ( $\Sigma$ fluid balance). Analyses were performed with the use of SPSS 22.0 (SPSS Inc., Chicago, IL) and GraphPad ${ }^{\circ}$ Prism 8.0 (GrapPad Software Inc., San Diego, CA, USA). Two-sided $P$ values $<0.05$ were considered statistically significant.

\section{Results}

In the study population, $77.3 \%$ of patients did not require ventilation for more than $24 \mathrm{~h}$, while 17.4 and $5.3 \%$ were on mechanical ventilation $24-48 \mathrm{~h}$ and $>48 \mathrm{~h}$, respectively. Baseline characteristics of patients according to time on mechanical ventilation are shown in Table 1. Patients requiring more than $48 \mathrm{~h}$ of ventilation had a lower eGFR, were more likely to be on maintenance dialysis and had similar SOFA at the ICU admission, not taking into account the renal component. Intraoperative condition that differed patients on prolonged ventilation $(>48 \mathrm{~h}$ ) were the longer anesthesia time, the higher dobutamine and noradrenaline dosage during $24 \mathrm{~h}$ following CABG, and longer hospitalization and ICU stay (Table 1).

Five patients (all from the CKD3-4 group) developed an impairment of renal function and required dialysis during hospitalization. These patients were characterized by higher serum creatinine $(p=0.045)$ and SOFA scores upon admission $(p=0.035)$ than those from the same group that did not required dialysis.

Although there was no difference in fluid balance during the first $24 \mathrm{~h}$ after surgery, patients on maintenance hemodialysis had a more positive fluid accumulation 48 $\mathrm{h}$ after CABG, even considering the negative balance promoted by ultrafiltration, as depicted in Fig. 2.

We found than only 10 patients presented FO (>10\%). FO was found in $4(1.8 \%), 2(4.1 \%)$ and $4(26.7 \%)$ patients on mechanical ventilation for $<24 \mathrm{~h}, 24-48$ and $>$ $48 \mathrm{~h}$, respectively $(p=0.001)$, as shown in Fig. 3. In addition, patients with FO $>10 \%$ were more likely to be on maintenance hemodialysis $(16.1 \%$ on hemodialysis vs. $3.6 \%$ of patients with CKD not on dialysis and $1.2 \%$ of patients with normal renal function, $p=0.0001)$.

Ventilation time correlated with eGFR $(r=-0.183, p=$ $0.004)$, SOFA at admission $(r=0.185, p=0.002)$ and on the first day after surgery with and without the renal component $(r=0.482, p=0.0001$ and $r=0.505, p=0.0001$, respectively), hospitalization time $(r=0.230, p=0.0001)$ and ICU stay $(r=0.326, p=0.0001)$. There was no significant association between time on mechanical ventilation and pneumonia $(p=0.389)$, diabetes $(p=0.453)$, hypertension 
Table 1 Patient baseline characteristics, according to time on mechanical ventilation

\begin{tabular}{|c|c|c|c|c|}
\hline Baseline characteristics & Less than $24 \mathrm{~h} \boldsymbol{N}=218$ & $24-48 \mathrm{~h} \boldsymbol{N}=49$ & More than $48 \mathrm{~h} \boldsymbol{N}=15$ & $p$ \\
\hline Age, years & $63 \pm 9$ & $62 \pm 8$ & $64 \pm 9$ & 0.844 \\
\hline Weight, kg & $76 \pm 14$ & $77 \pm 13$ & $72 \pm 9$ & 0.577 \\
\hline Male gender, \% & 72.5 & 81.6 & 80 & 0.364 \\
\hline Diabetes, \% & 52.3 & 61.2 & 46.7 & 0.453 \\
\hline Ejection fraction, \% & $55.9 \pm 11.4$ & $52.7 \pm 15.2$ & $56.5 \pm 11.6$ & 0.307 \\
\hline eGFR, $\mathrm{ml} / \mathrm{min} / 1.73 \mathrm{~m}^{2}$ & $69.2 \pm 18.6^{+}$ & $63.8 \pm 19.8^{\dagger}$ & $44.2 \pm 14.8^{*}$ & 0.0001 \\
\hline Serum creatinine at admission, $\mathrm{mg} / \mathrm{dl}$ & $1.13 \pm 0.4^{\dagger}$ & $1.26 \pm 0.5^{\dagger}$ & $1.69 \pm 0.8^{*}$ & 0.0001 \\
\hline Patients, from each group $\%$ & & & & 0.0001 \\
\hline Control $(\mathrm{N}=167)$ & 83.8 & 15.6 & 0.6 & \\
\hline CKD3-4 (N = 84) & 67.9 & 21.4 & 10.7 & \\
\hline Dialysis $(N=31)$ & 67.7 & 16.1 & 16.1 & \\
\hline \multicolumn{5}{|l|}{ Surgery and ICU conditions } \\
\hline ACC time, $\min$ & $69.1 \pm 28.9$ & $72.6 \pm 26.0$ & $69.6 \pm 20.1$ & 0.758 \\
\hline CPB time, $\min$ & $92.1 \pm 35.9$ & $93.2 \pm 30.3$ & $95.5 \pm 14.7$ & 0.932 \\
\hline Surgery time, $\min$ & $383 \pm 97$ & $377 \pm 115$ & $433 \pm 173$ & 0.173 \\
\hline Diuresis IPO, $\mathrm{ml} / \mathrm{kg} / \mathrm{h}$ & $0.73 \pm 0.35$ & $0.70 \pm 0.38$ & $0.57 \pm 0.63$ & 0.274 \\
\hline Diuresis 1 st day after surgery, $\mathrm{ml} / \mathrm{kg} / \mathrm{h}$ & $1.18 \pm 0.46$ & $1.18 \pm 0.49$ & $0.83 \pm 0.77^{*}$ & 0.035 \\
\hline Intra-aortic balloon pump, \% & 4.2 & 7.1 & 0 & 0.248 \\
\hline Fluid balance $24 \mathrm{~h}$ after surgery, $\mathrm{L}$ & $2.5 \pm 1.2$ & $2.7 \pm 1.2$ & $2.7 \pm 1.3$ & 0.749 \\
\hline Anesthesia time, $\min$ & $412 \pm 86^{\dagger}$ & $417 \pm 98^{\dagger}$ & $482 \pm 164^{*}$ & 0.021 \\
\hline Ventilation time, hours & $8(6,10)^{\dagger}$ & $16(14,19)^{* \dagger}$ & $62(42,160)^{*}$ & 0.0001 \\
\hline SOFA on the ICU admission & $0(0,1)^{\dagger}$ & $1(0,1.22)^{\dagger}$ & $3(1,4)^{*}$ & 0.0001 \\
\hline SOFA without renal component & $0(0,0)$ & $0(0,1)$ & $0(0,1)$ & 0.326 \\
\hline \multicolumn{5}{|l|}{ SOFA by organ } \\
\hline Renal & $0(0,1)$ & $0(0,1)^{\dagger}$ & $1(1,4)^{*}$ & 0.0001 \\
\hline Hematologic & $0(0,0)$ & $0(0,0)$ & $0(0,1)$ & 0.106 \\
\hline Neurologic & $0(0,0)$ & $0(0,0)$ & $0(0,0)$ & 1 \\
\hline Respiratory & $0(0,0)$ & $0(0,0)$ & $0(0,0)$ & 0.630 \\
\hline Hepatic & $0(0,0)$ & $0(0,0)$ & $0(0,0)$ & 0.863 \\
\hline Cardiovascular & $0(0,0)$ & $0(0,0)$ & $0(0,1)$ & 0.092 \\
\hline Dobutamine dose $24 \mathrm{~h}$ after surgery, $\mathrm{ml} / \mathrm{kg} / \mathrm{min}$ & $7.5 \pm 5.0^{\dagger}$ & $9.9 \pm 5.5^{* \dagger}$ & $12.4 \pm 6.0^{*}$ & 0.0001 \\
\hline Noradrenaline dose $24 \mathrm{~h}$ after surgery $\mathrm{ml} / \mathrm{kg} / \mathrm{h}$ & $0.16 \pm 0.14^{\dagger}$ & $0.27 \pm 0.19^{* \dagger}$ & $0.56 \pm 0.13^{*}$ & 0.0001 \\
\hline Volume intake in 5 days, $\mathrm{L}$ & $7.6 \pm 1.9$ & $7.3 \pm 1.8$ & $8.1 \pm 0.9$ & 0.725 \\
\hline Cumulative fluid balance in 5 days, $\mathrm{L}$ & $-1.3(-2.4,-0.3)$ & $-1.6(-2.6,0.3)$ & $0.39(-2.7,3.7)$ & 0.109 \\
\hline$\Sigma$ Fluid balance, $\mathrm{L}$ & $1.2(-0.4,2.4)$ & $1.0(-1.2,2.3)$ & $1.8(0.9,7.8)$ & 0.208 \\
\hline Fluid overload/body weight, $\%$ & $-1.9(-3.0,-0.5)$ & $-1.8(-3.5,0.5)$ & $0.6(-3.4,5.6)$ & 0.109 \\
\hline Hospitalization time, days & $14(10,20)$ & $16(12,29)^{*}+$ & $23(17,43)^{*}$ & 0.001 \\
\hline ICU stay, days & $3(2,5)^{\dagger}$ & $5(3,7)^{*}+$ & $8(5,27)^{*}$ & 0.0001 \\
\hline
\end{tabular}

Data are presented as mean SD, \% or median (25-75)

ACC time aortic cross-clamping time, CPB time cardiopulmonary bypass time, SOFA Sequential Organ Failure Assessment, ICU intensive care unit

${ }^{*} p<0.05$ vs. Less than $24 \mathrm{~h} ; \mathrm{\dagger} p<0.05$ vs. More than $48 \mathrm{~h}$

( $p=0.752)$, dyslipidemia $(p=0.373)$, obesity $(p=0.624)$, history of previous cardiac surgery $(p=0.464)$, ischemic cardiomyopathy $(p=0.718)$, history of previous myocardium infarction $(p=0.874)$, history of cancer $(p=$
$0.372)$, urinary infection $(p=0.843)$, and operative site infection $(p=0.105)$.

In a multivariate analysis, factors found to be independently associated with time ventilation time were the 

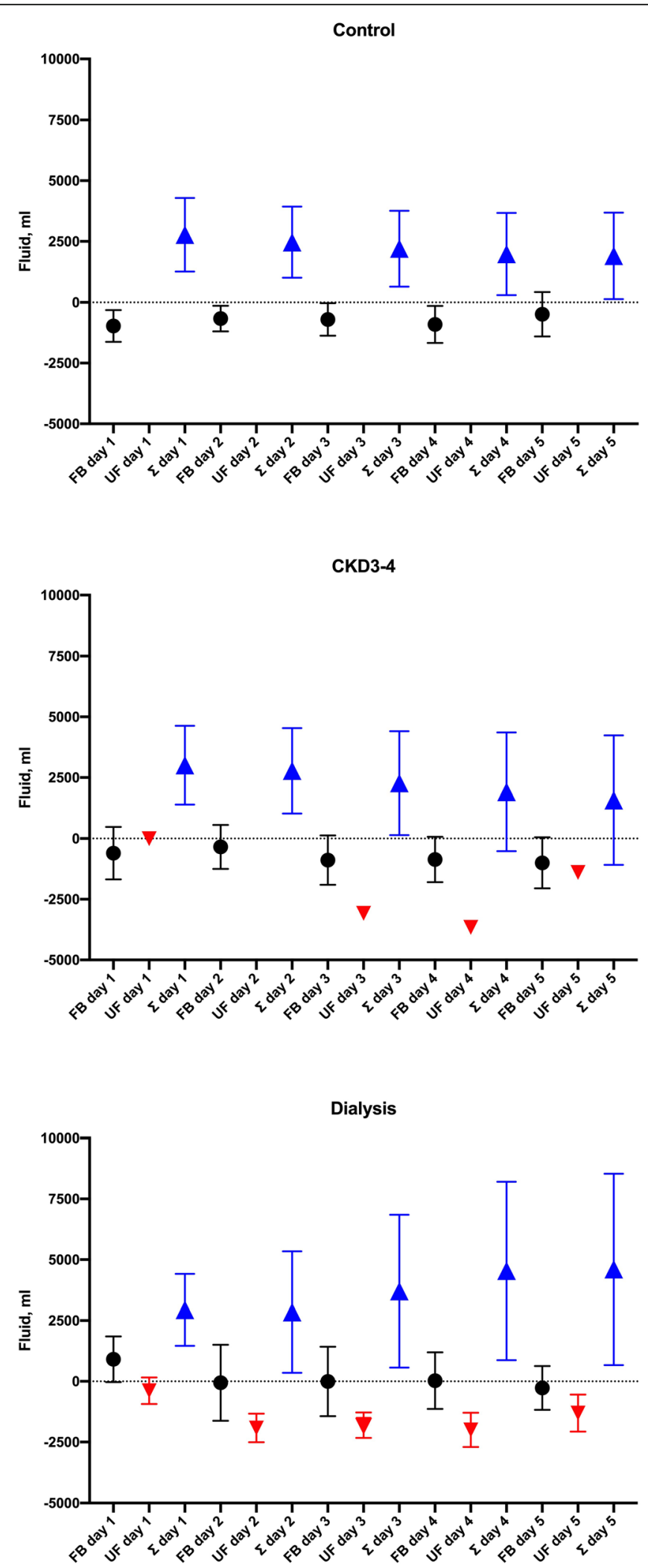

Fig. 2 (See legend on next page.) 
(See figure on previous page.)

Fig. 2 Fluid accumulation in the 5 days following coronary artery bypass surgery according to renal function. Daily fluid balance (result of intake and output) is represented by a dark circle. Ultrafiltration promoted by dialysis is represented by a red triangle, and $\Sigma$ fluid balance (cumulative result of intake and output) is represented by a blue triangle. Of note, patients with normal renal function (reference - upper panel) were capable to maintain fluid balance close to zero. Patients with stages 3-4 chronic kidney disease - middle panel) presented a slightly positive fluid balance and some of them needed dialysis due to acute renal failure. Patients on maintenance hemodialysis (bottom panel) exhibited a positive and cumulative fluid balance despite an ultrafiltration promoted by dialysis

$\Sigma$ fluid balance $(p=0.011)$, group of patients $(p=0.039)$, and the SOFA on the first day after surgery $(p=0.0001)$, in a model adjusted for anesthesia time, noradrenaline and dobutamine dosage (Table 2).

We further performed a multivariate analysis including only patients on maintenance hemodialysis; the time on mechanical ventilation was dependent on the $\Sigma$ fluid balance and the SOFA on the first day after surgery (without the renal component) that together accounted for $52.4 \%$ in the variability of the time on mechanical ventilation (Table 2).

\section{Discussion}

Fluid overload in patients on dialysis is a therapeutic challenge as it can lead to several unfavourable outcomes [14]. In this prospective study, we made the novel observation that fluid accumulation was directly associated with prolonged mechanical ventilation in patients in this population. We also observed that the time spent since the CABG until the first hemodialysis session was another independent predictor factor of prolonged ventilation. Whether early dialysis would change this scenario warrants further studies.

PMV has been associated with fluid overload. In the present study, patients who required more than $48 \mathrm{~h}$ of ventilation had lower eGFR and most of them were from the dialysis group. The propensity to vascular congestion

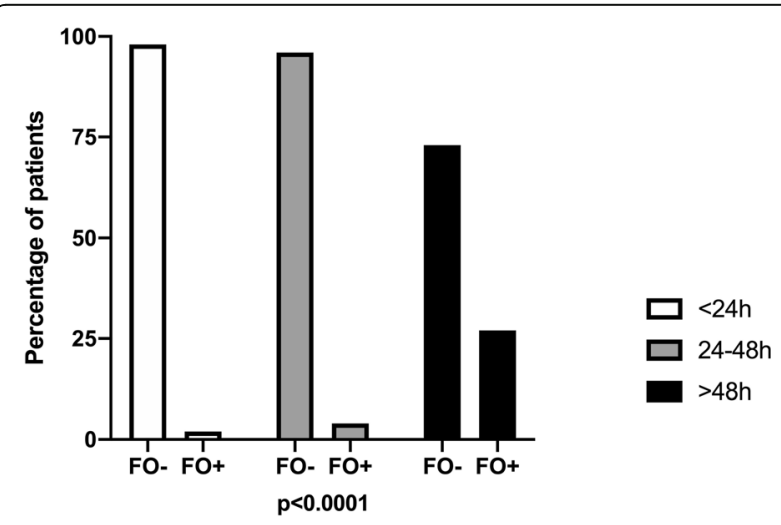

Fig. 3 Association between fluid overload (FO) and time on mechanical ventilation. Patients on mechanical ventilation for $<24 \mathrm{~h}$, 24-48 $\mathrm{h}$ and $>48 \mathrm{~h}$ were represented by white, grey and black bars, respectively and alveolar volume overload in patients with end-stage renal helps justify these data [15]. Canver et al. showed that patients with renal failure had 12.8 odds to develop respiratory failure [2]. Even in patients with normal renal function, fluid overload is associated with extravasation into the interstitial space and reduction of capillary blood flow leading to renal ischemia $[8,10]$.

A previous prospective study has shown that progressive fluid overload and changes in creatinine correlated with post-cardiac surgery mortality [16]. Indeed, fluid overload was associated with prolonged length in ICU and it was identified as an earlier and more sensitive prognostic marker than serum creatinine [16]. Heringlake et al. in a post-hoc study enrolling 584 patients showed that $7.4 \%$ of patients developed AKI stage 3 and initiated dialysis $26.5 \mathrm{~h}$ after surgery [4]. The early initiation of dialysis showed a survival advantage for this population. However, the ideal moment to initiate dialysis is controversial, and there is opposition to early dialysis because it could expose patients to potential harms such as intradialytic hypotension [15]. Chronic or acute functional changes at the renal system were associated with failure or delayed extubation in clinical and surgical patients $[6,17]$. It is possible to perceive the narrow relationship between the renal and pulmonary system and unclear unrecognized risk factors, which need to be explored.

Despite ultrafiltration during the hospitalization stay, patients on dialysis developed FO, and can cause extravasation of fluid into interstitial space, increasing extravascular lung water, decreasing lung compliance and impairing oxygenation, which results in respiratory failure and impairment of multiple organ systems $[8,10,17]$. Our study showed an association between fluid accumulation, ICU stay and ventilation time. Fluid accumulation became significant after $24 \mathrm{~h}$ post-operative, which was remarkable in patients with CKD3-4 and in those on dialysis. In a retrospective study that enrolled 567 patients submitted to cardiovascular surgery, the delay to reach a negative fluid balance during the first 3 days was associated with higher hospital length of stay and mortality [10]. Our data showed that patients with normal renal function had an effective homeostasis mechanism that promotes negative balance. However, some patients with CKD3-4 had a progressive fluid accumulation and needed dialysis. In patients on maintenance hemodialysis, this scenario was worse as FO persisted despite consecutive ultrafiltration, 
Table 2 Multivariate analysis of factors associated with prolonged time on ventilation in the entire population and among patients on maintenance hemodialysis

\begin{tabular}{|c|c|c|c|}
\hline Parameter & Standardized $\beta$ coefficient & Partial correlation & $p$ \\
\hline \multicolumn{4}{|l|}{ Model 1: Entire population } \\
\hline$\Sigma$ fluid balance, $\mathrm{ml}$ & 0.171 & 0.172 & 0.004 \\
\hline Group of patients: reference, CKD3-4 and dialysis & 0.182 & 0.183 & 0.002 \\
\hline SOFA on the first day after surgery & 0.312 & 0.314 & 0.0001 \\
\hline \multicolumn{4}{|l|}{ Model 2: Patients on hemodialysis } \\
\hline$\Sigma$ fluid balance, $\mathrm{ml}$ & 0.284 & 0.497 & 0.049 \\
\hline Time from surgery to $1 \mathrm{st} \mathrm{HD}, \mathrm{h}$ & 0.289 & 0.332 & 0.038 \\
\hline SOFA without renal component & 0.549 & 0.627 & 0.0001 \\
\hline
\end{tabular}

Model 1: $r=0.369, r^{2}=0.136$ and adjusted $r^{2}=0.130 ; p=0.0001$. Other variables in the model: anesthesia time, noradrenaline and dobutamine dose $24 \mathrm{~h}$ after surgery

Model 2: $r=0.757, r^{2}=0.574$ and adjusted $r^{2}=0.524 ; p=0.0001$. Other variable in the model: age

$H D$ hemodialysis, SOFA Sequential Organ Failure Assessment

measured by $\Sigma$ fluid accumulation. The high amplitude fluctuation in the fluid has been related to 2.75 times higher all-cause and cardiovascular mortality in patients on maintenance hemodialysis [14]. The hemodynamic instability after CABG despite the fluid overload might postpone the decision to initiate dialysis in the clinical practice [16]. Nevertheless, based on our findings, fluid accumulation correlated with ventilation time in patients on dialysis, which denotes the importance of hemodialysis in this group. $\Sigma$ fluid accumulation was independently associated with prolonged time on mechanical ventilation. Moreover, the longer the time spent to initiate the first dialysis session, the longer the ventilation time.

Our results denote that fluid accumulation is a marker of prolonged ventilation in patients on maintenance hemodialysis submitted to an elective CABG. Therefore, our study opens an avenue for research on the ideal time to initiate dialysis after such surgery, in an attempt to reduce fluid accumulation and avoid extending ventilation time.

This study is subject to some limitations: first, the acid-base equilibrium was not analyzed; second, the moment to initiate dialysis was dependent on the physician in charge; third, the daily weight was not available; fourth, due to a limited sample size $(N=5)$ we could not adjust for acute renal failure that occurred in the CKD3-4 group, and finally, due to the study design we were not able to access if early dialysis initiation would short the time on mechanical ventilation. The strength of our study was its prospective design and the daily follow-up by the same observer.

\section{Conclusions}

Our findings suggest that prolonged ventilation time in patients on maintenance hemodialysis might be directly dependent on the fluid overload and the time spent until the first hemodialysis session.

\section{Abbreviations}

CABG: Coronary artery bypass grafting; CKD: Chronic kidney disease; eGFR: Estimated glomerular filtration rate; ICU: Intensive care unit; PMV: Prolonged mechanical ventilation; SOFA: Sequential organ failure assessment; $\Sigma$ : Sum of fluid balance

\section{Acknowledgements}

not applicable.

\section{Authors' contributions}

SCS, RMAM, FCC and RME conceived the idea; SCS collected the data; SCS, RGR, FAG, LAH, FMC, RMAM and RME interpreted the data, discussed the results and commented on the manuscript; SCS and RME performed the analyses; SCS, RMAM and RME drafted the manuscript; all authors approved the final version.

\section{Funding}

FMCC, RMAM and RME are supported by CNPq, Conselho Nacional de Desenvolvimento Científico e Tecnológico. This financial support had no role in the study design, collection, analysis and interpretation of the data, the writing of the report, and the decision to submit the report for publication.

Availability of data and materials

The datasets analysed during the current study are available from the corresponding author on reasonable request.

\section{Ethics approval and consent to participate}

The Local Ethics Committee at the Hospital das Clínicas da Faculdade de Medicina da Universidade de São Paulo has approved the research (Cappesq \#45529815.6.0000.0068). The Ethics Committee waived the need for informed consent since data were extracted from charts anonymously.

\section{Consent for publication}

not applicable.

\section{Competing interests}

nothing to declare.

\section{Author details}

IInstituto do Coração, Hospital das Clinicas HCFMUSP, Universidade de São Paulo, São Paulo, Brazil. ${ }^{2}$ Nephrology, Hospital das Clinicas HCFMUSP, Universidade de São Paulo, São Paulo, Brazil. ${ }^{3}$ Universidade Nove de Julho (UNINOVE), São Paulo, Brazil. 
Received: 26 November 2019 Accepted: 27 February 2020

Published online: 07 March 2020

\section{References}

1. Cooper WA, O'Brien SM, Thourani VH, Guyton RA, Bridges CR, Szczech LA, Petersen R, Peterson ED. Impact of renal dysfunction on outcomes of coronary artery bypass surgery: results from the Society of Thoracic Surgeons National Adult Cardiac Database. Circulation. 2006;113(8):1063-70.

2. Canver CC, Chanda J. Intraoperative and postoperative risk factors for respiratory failure after coronary bypass. Ann Thorac Surg. 2003;75(3):853-7 discussion 857-858.

3. Suarez-Pierre A, Fraser CD, Zhou X, Crawford TC, Lui C, Metkus TS, Whitman GJ, Higgins RS, Lawton JS. Predictors of operative mortality among cardiac surgery patients with prolonged ventilation. J Card Surg. 2019;34(9):759-66.

4. Heringlake M, Nowak Y, Schön J, Trautmann J, Berggreen AE, Charitos El, Paarmann H. Postoperative intubation time is associated with acute kidney injury in cardiac surgical patients. Crit Care. 2014;18(5):547.

5. Bouabdallaoui N, Stevens SR, Doenst T, Wrobel K, Bouchard D, Deja MA, Michler RE, Chua YL, Kalil RAK, Selzman CH, et al. Impact of intubation time on survival following coronary artery bypass grafting: insights from the surgical treatment for ischemic heart failure (STICH) trial. J Cardiothorac Vasc Anesth. 2018;32(3):1256-63.

6. Gumus F, Polat A, Yektas A, Totoz T, Bagci M, Erentug V, Alagol A. Prolonged mechanical ventilation after CABG: risk factor analysis. J Cardiothorac Vasc Anesth. 2015;29(1):52-8.

7. Barmparas G, Liou D, Lee D, Fierro N, Bloom M, Ley E, Salim A, Bukur M. Impact of positive fluid balance on critically ill surgical patients: a prospective observational study. J Crit Care. 2014;29(6):936-41.

8. Maes T, Meuwissen A, Diltoer M, Nguyen DN, La Meir M, Wise R, Spapen H, Malbrain MLNG, De Waele E. Impact of maintenance, resuscitation and unintended fluid therapy on global fluid load after elective coronary artery bypass surgery. J Crit Care. 2019:49:129-35.

9. Shim HJ, Jang JY, Lee SH, Lee JG. The effect of positive balance on the outcomes of critically ill noncardiac postsurgical patients: a retrospective cohort study. J Crit Care. 2014;29(1):43-8.

10. Li C, Wang H, Liu N, Jia M, Zhang H, Xi X, Hou X, Workgroup BAKITB. Early negative fluid balance is associated with lower mortality after cardiovascular surgery. Perfusion. 2018;33(8):630-7.

11. Saleh HZ, Shaw M, Al-Rawi O, Yates J, Pullan DM, Chalmers JA, Fabri BM. Outcomes and predictors of prolonged ventilation in patients undergoing elective coronary surgery. Interact Cardiovasc Thorac Surg. 2012;15(1):51-6.

12. Levey AS, Stevens LA, Schmid CH, Zhang YL, Castro AF 3rd, Feldman HI, Kusek JW, Eggers P, Van Lente F, Greene T, et al. A new equation to estimate glomerular filtration rate. Ann Intern Med. 2009;150(9):604-12.

13. Bouchard JE, Mehta RL. Fluid balance issues in the critically ill patient. Contrib Nephrol. 2010;164:69-78.

14. Siriopol D, Siriopol M, Stuard S, Voroneanu L, Wabel P, Moissl U, Voiculescu D, Covic A. An analysis of the impact of fluid overload and fluid depletion for all-cause and cardiovascular mortality. Nephrol Dial Transplant. 2019;34: 1385-93.

15. Visconti L, Santoro D, Cernaro V, Buemi M, Lacquaniti A. Kidney-lung connections in acute and chronic diseases: current perspectives. J Nephrol. 2016;29(3):341-8.

16. Stein A, de Souza LV, Belettini CR, Menegazzo WR, Viégas JR, Costa Pereira EM, Eick R, Araújo L, Consolim-Colombo F, Irigoyen MC. Fluid overload and changes in serum creatinine after cardiac surgery: predictors of mortality and longer intensive care stay. A prospective cohort study. Crit Care. 2012 16(3):R99

17. Ghosh S, Chawla A, Mishra K, Jhalani R, Salhotra R, Singh A. Cumulative fluid balance and outcome of Extubation: a prospective observational study from a general intensive care unit. Indian J Crit Care Med. 2018;22(11):767-72.

\section{Publisher's Note}

Springer Nature remains neutral with regard to jurisdictional claims in published maps and institutional affiliations.

\section{Ready to submit your research? Choose BMC and benefit from:}

- fast, convenient online submission

- thorough peer review by experienced researchers in your field

- rapid publication on acceptance

- support for research data, including large and complex data types

- gold Open Access which fosters wider collaboration and increased citations

- maximum visibility for your research: over $100 \mathrm{M}$ website views per year

At BMC, research is always in progress.

Learn more biomedcentral.com/submissions 